Article

\title{
Predicting Financial Distress in the Hong Kong Growth Enterprises Market from the Perspective of Financial Sustainability
}

\author{
Hui Hu ${ }^{1, *}$ and Milind Sathye ${ }^{2, *}$
}

1 Economics and Management School, Wuhan University, Wuhan 430072, China

2 Faculty of Business, Government and Law, University of Canberra, Bruce ACT 2601, Australia

* Authors to whom correspondence should be addressed; E-Mails: hui.hu@whu.edu.cn (H.H.); milind.sathye@canberra.edu.au (M.S.); Tel.: +86-27-6875-3122 (H.H.); +61-2-6201-5489 (M.S.).

Academic Editor: Giuseppe Ioppolo

Received: 19 October 2014 / Accepted: 16 January 2015 / Published: 23 January 2015

\begin{abstract}
The present study, according to our knowledge, is the first attempt to establish a financial distress prediction model for a unique set of enterprises, which are the enterprises listed on the specialized Hong Kong Growth Enterprise Market. It also makes an analysis of corporate financial sustainability and its relationship to financial distress prediction. The logistic regression and jackknife method are used to test the predictability of various models with data drawn from the Growth Enterprise Market for the years 2000-2010. The study finds that a model that includes firm-specific financial variables, firm-specific non-financial variables and a macro-economic variable is a better predictor of financial distress than is a model that includes only the first set of variables or a model that includes the latter two sets of variables. It also finds that a model that includes the latter two sets of variables is a better predictor of financial distress than is a model that includes only the first set of variables. These findings are vital for financial sustainability, as investors, policymakers, auditors and stakeholders of this market would find the conclusions emanating from the study extremely useful.
\end{abstract}

Keywords: financial distress; prediction; Growth Enterprise Market; financial sustainability; financial variable; non-financial variable; macro-economic variable 


\section{Introduction}

Since Hong Kong was handed over to China in 1997, Hong Kong has become an important capital raising centre for Chinese enterprises. However, in order to obtain a listing on the Hong Kong Stock Exchange (HKSE), the enterprises are required to achieve a record of at least a three years' trading history. Since most small and medium enterprises are unable to take advantage of the HKSE, the Hong Kong Growth Enterprise Market (GEM) was established in 1999 to bridge this gap [1].

The Hong Kong GEM is important for three reasons. First, the GEM was established for enterprises that are unable to meet the profitability and track record requirement. The GEM has removed the entry barriers for listing on the market for growth enterprises, which either have growth potential or use high technology [2]. Second, the GEM is considered to be a 'high risk, high growth' market, which is unique, as no other such specialist market for high risk growth enterprises exists. Lastly, technology companies dominate the GEM, and their continued health is essential to both Hong Kong and China's global economic competitiveness [3]. Consequently, it is important that these enterprises are financially sustainable.

Financial sustainability is defined as the likelihood that a business is self-sufficient without any external support [4]. Chan et al. [5] find that most newly-listed stocks of growth enterprises on the Hong Kong GEM are underperforming. They raise questions about those enterprises' financial sustainability. As Chen et al. [6] point out, high financial risk, which ultimately impacts financial sustainability, also makes investors more cautious about investing in the Hong Kong GEM. Financial sustainability becomes important for growth enterprises for another reason. Although an enterprise is usually required to disclose a three-year profit record before being listed on the HKSE, such a requirement is absent for the GEM. The opaqueness makes the financial sustainability of the GEM's enterprises a significant issue. Hence, studying the financial sustainability of such enterprises becomes crucial.

In the literature, severe financial distress usually threatens financial sustainability. The establishment of an early warning mechanism for corporate financial distress can promote the financial sustainability of enterprises [7-9]. If a model to predict financial distress in the GEM could be developed, it would help not only the investors, but also the market supervisors. Given the particularly strong relationship between Hong Kong and mainland China, the developed financial distress prediction model could help predict the financial distress in mainland China's newly-established GEM.

In the present study, we define a distressed growth enterprise as an enterprise that has filed for bankruptcy, undergone cancellation of listing pursuant to delisting procedures under the GEM Listing Rules or has had its securities trading suspended by the GEM for at least three months due to disobeying GEM Listing Rules [10]. Most studies have used firm-specific financial variables (FVs) to predict financial distress. Some recent studies have also made use of firm-specific non-financial variables (NFVs) and macroeconomic variables (MEVs) [11,12]. However, the impact of the use of all three sets of variables on improving the predictive power has not been well examined in prior research. This study examines three financial distress predicting models. The first one is based on FVs only (Model 1). The second one uses both NFVs and MEV (Model 2), and the third model uses all three sets of variables (Model 3).

The major aim of the present study is to successfully predict financial distress in the GEM. To achieve this aim, the data of 150 firms listed on the Hong Kong GEM between 2000 and 2010 were analysed using logistic regression and the jackknife method. Our study not only considers all three sets of 
variables, but also, for the first time in the literature, establishes financial distress prediction models for a special market not explored hitherto, that is for the Hong Kong GEM. Growth enterprises have several distinguishing features outlined above that make them unique. Hence, we need an appropriate model to capture these features. The model would be a useful tool for maintaining the financial sustainability of listed companies and the market.

The remainder of the article is organized as follows. Section 2 reviews previous literature and develops three hypotheses. Section 3 presents the data and methods used in this study. Data analysis results are presented in Section 4. Section 5 discusses the results, and the final section concludes.

\section{Relevant Literature and Hypotheses Development}

The literature on the definition of corporate financial distress is extensive, encompassing many definitions of what constitutes financial distress. A financially-distressed enterprise is commonly defined as an enterprise that has filed for bankruptcy [13-17]. Kuo et al. [18] define the distressed firm as a firm involved in dishonouring bills or checks, delaying repayment of banks' loans, having a poor credit history, having bank accounts rejected or having a net worth less than half of its real assets. Wu [19] defines a distressed firm in the context of the Taiwan Stock Exchange as a listed firm that has experienced operational difficulties or for which authorities have judicially declared a special stock arrangement. For a study on predicting the financial distress of companies listed on the Johannesburg Stock Exchange in South Africa, financial distress is defined as a state in which a firm cannot continue to exist in its current form and has experienced bankruptcy, delisting or a major organizational restructuring [20]. Similarly, Cheng et al. [21] identify a firm as distressed if it has filed for bankruptcy, been placed on a suspension of trading list, altered a trading method or been involved in unusual actions, such as a cease trading order or delisting.

The literature on financial distress prediction has developed in three stages. In the first stage, the focus was solely on financial ratios as predictors of financial distress. Beaver [13] used financial ratios to predict the failure of firms, and found that financial ratios are useful in predicting a firm's failure. Beaver [13], however, found that a firm's cash flow-to-total debt ratio has greater predictive ability than do liquid asset ratios. Altman [15] improved upon Beaver's [13] work by conducting rigorous testing through multiple discriminant analysis and suggested that only five ratios, working capital-to-total assets ratio, retained earnings-to-total assets ratio, earnings before interest and taxes-to-total assets ratio, market value of equity-to-book value of total debt ratio, and sales-to-total assets ratio, are significant in predicting financial distress. Altman et al. [16] further improved Altaman's [14] model and developed a new ZETA credit risk model using seven variables to predict corporate bankruptcy. Ohlson [17], on the other hand, identified four basic financial factors that can predict a firm filing for bankruptcy within a year.

In the second stage, studies included MEVs in addition to FVs for financial distress prediction. Mensah [22] suggested that the structure and accuracy of prediction models differ across diverse macroeconomic environments, and those different prediction models are appropriate for enterprises in different industrial sectors. Dionne et al. [23] established a hybrid model by including real GDP growth, as well as some FVs. According to their study, real GDP growth is negatively correlated with the likelihood of the firm facing financial difficulties. 
In the third stage, studies examined the impact of NFVs on distress prediction. These include studies by Slowinski and Zopounidis [24] and Dimitras et al. [25], who accord more importance to qualitative attributes than to financial attributes. In addition, the results of Wilkins's [26] study suggest that the auditor's opinion is an important predictor of future financial distress for technically-distressed firms. Chen [27] also argued that incorporating the corporate governance measure into the analysis of logistic regression could improve the predictive accuracy of corporate financial distress. For small- and medium-sized enterprises (SMEs), Kuo et al. [18] found both FVs and NFVs useful in classifying distressed and successful SMEs. Similarly, both Wu [19] and Ooghe and Balcaen [28] have indicated that a prediction model based on both FVs and NFVs or a combination of these variables can lead to superior predictive results.

As can be seen from above, most research studies on financial distress focus their attention on the predictive ability of FVs. Many other financial distress studies have examined FVs, NFVs and MEVs separately or formulated their research by combining two out of these three sets of variables, but only two recent studies $[11,12]$ covered all three sets of variables. However, these studies have focused on firms listed on the Taiwanese and Indonesian stock markets. These markets are different from the Hong Kong GEM, which is a special and separate market for growth enterprises only.

A study of the Hong Kong GEM is important for several reasons. First, as stated above, the Hong Kong GEM has not been subjected to such an analysis so far, and ours is the first study, to our knowledge, of financial distress prediction in the context of the GEM. Second, the GEM is the engine of growth in any economy. Chinese GEMs, for example, have played a vital role in promoting rapid growth and maintaining financial sustainability during China's economic transition [3]. Third, the GEM provides a fund-raising venue and an exit ground, especially for high-growth and high-risk enterprises. A prediction model for financial distress would considerably benefit investors and policymakers. Finally, we make important contributions to advance the extant theory of financial distress prediction.

\subsection{Overview of Financial Distress Prediction Models}

Aziz and Humayon [29] have compiled an extensive literature review of 46 articles that reported 89 previous empirical studies on predicting corporate financial distress. According to their statistics, $64 \%$ of total previous studies used statistical distress prediction models; about a quarter of all previous studies applied artificial intelligent expert system models, and only $11 \%$ of the previous studies used the theoretical models. However, these researchers found that the average predictive accuracy of these three categories of models is quite close. The range of these three models' predictive accuracy is from $84 \%$ to $88 \%$.

In the present study, the most frequently-used prediction models, the statistical distress prediction models, are deployed to predict the financial distress of growth enterprises. Of the two types of statistical distress prediction models (multivariate discriminant and logistic), the logistic model has two distinct advantages: first, the logistic model does not rely on the assumption of normality for the sample data; second, the logistic model does not require an equal dispersion matrix [30]. In other words, the logistic model is far less demanding than the multivariate discriminant model. Because of the advantages of the logistic model, the present study constructs a financial distress model for growth enterprises based on logistic regression. 


\subsection{Hypotheses Development}

Many prior studies have used FVs as the major predictors of corporate financial distress [15,16,18,19,27,31-33]. Recent studies, however, contend that NFVs and MEVs also need to be considered for financial distress prediction. Back [34], for example, used only NFVs in the financial distress prediction model and found that the model has better predictive ability than does a model that includes only FVs. Foster [35] found that multivariate models that include MEVs and FVs have better financial distress prediction ability than does a model that includes only FVs. Pranowo et al. [12] used FVs, NFVs and MEVs and found that only FVs are significant predictors of financial distress, in the Indonesian Stock Exchange, which is not a separate exchange, such as the HKGEM.

In a Canadian study, Dionne et al. [23] used a hybrid model that included one MEV, real GDP growth and several FVs and found that such a model has better predictive ability of financial distress. Consequently, the present study posits that a corporate financial distress model covering all three sets of variables - that is, FVs, NFVs and MEVs - would have even better predictive ability. We test this proposition in the context of GEM and formulate the following three hypotheses.

H1: There is no difference in the financial distress predictive ability of a model that contains only FVs (Model 1) vis-à-vis the model that contains only NFVs and MEVs (Model 2).

$\mathrm{H} 2$ : There is no difference in the financial distress predictive ability of a model that contains only FVs (Model 1) vis-à-vis the model that contains FVs, NFVs and MEVs (Model 3).

H3: There is no difference in the financial distress predictive ability of Model 2 and Model 3.

\section{Data and Method}

\subsection{Selection of Sample}

Our sampling frame consists of firms listed on the Hong Kong GEM during the period from 2000-2010. In the whole population, the firms that satisfied the criterion for financial distress were grouped as "distressed enterprises", and the rest were grouped as "non-distressed enterprises". In the present study, we used the random sampling technique, which is a probability sampling technique. Following Lennox [36], the sample consists of distressed enterprises and non-distressed enterprises in proportion to their ratio in the actual population. Based on the random sample selection, we restricted our sample to 150 growth enterprises, consisting of 45 distressed enterprises (using our definition of a distressed enterprise) and 105 non-distressed enterprises. We examined the data for all 150 firms in our sample for the years from 2000 to 2010 . For distressed firms, the year when they became distressed was coded as $\mathrm{t}$ and the data for the year $\mathrm{t}^{-1}$ were used.

\subsection{Selection of Financial Distress Predictors}

It is usual to classify FVs into three types: profitability ratios, solvency ratios and liquidity ratios [37,38]. The present study used these three types of FVs as financial distress predictors.

Profitability ratios measure the firm's ability to generate profit for a given period of time. A firm's profit situation can influence the firm's liquidity position and its ability to obtain equity and debt 
financing [37]. The current study used the gross profit rate of 150 firms in the sample as the profitability ratio.

Liquidity ratios measure the short-term ability of the firm to pay its maturing obligations and to meet unexpected needs for cash [37]. The commonly-used measure of liquidity, that is the current ratio of the sample firms, was used in the present study.

Solvency ratios measure the firm's ability to repay the face value of the debt at maturity and to pay the interest when it comes due. In other words, solvency ratios measure the ability of a firm to survive over a long period of time [37]. The current study used debt to total assets, representing the solvency ratio.

Prior studies have also deployed several NFVs, such as management measures, corporate governance variables, audit variables and ownership, to forecast a firm's distress [39,40]. Based on the information of growth enterprises and related prior studies, the present study selected two NFVs: the frequency of the firm changing its auditor(s) and the frequency of the firm's auditors' report including a qualified opinion and/or explanatory paragraph.

Mensah [22] also notes that the performance of a firm is usually affected by a few MEVs. Based on the availability of data on the MEVs and prior studies on the prediction of corporate financial distress, the present study selected the Business Climate Index to predict financial distress.

To conclude, we used FVs (gross profit rate, current ratio, debt to total assets), NFVs (the frequency of the firm changing its auditor(s), the frequency of the firm's auditors' report including a qualified opinion and/or explanatory paragraph) and MEV (the Business Climate Index) to build financial distress prediction models. In Table 1, we summarize the statistical properties of all of the data that we used (except the financial distress dummy).

Table 1. Descriptive statistics.

\begin{tabular}{lcccc}
\hline \multicolumn{1}{c}{ Variable } & Mean & Standard Deviation & Minimum & Maximum \\
\hline Gross profit rate & 0.633 & 0.255 & -0.653 & 0.990 \\
\hline Current ratio & 1.304 & 0.381 & 0.341 & 2.178 \\
\hline Debt to total assets & 0.736 & 0.183 & 0.314 & 1.153 \\
\hline The frequency of the firm changing its auditor(s) & 0.253 & 0.557 & 0.000 & 1.000 \\
\hline $\begin{array}{l}\text { The frequency of auditors' report with qualified } \\
\text { opinion/explanatory paragraph including a }\end{array}$ & 0.113 & 0.318 & 0.000 & 1.000 \\
"qualified opinion" and/or explanatory paragraph & & & & \\
\hline \begin{tabular}{l} 
The Business Climate Index \\
\hline
\end{tabular} & 5.136 & 0.073 & 4.935 & 5.235 \\
\hline
\end{tabular}

\section{Analysis and Results}

The selected financial, non-financial and macroeconomic variables were used as independent variables for logistic regression analyses. The dependent variable is binary, that is whether the growth enterprise experienced distress or not (distressed $=1$, non-distressed $=0$ ). We then used logistic regression analyses to establish three types of financial distress models. The first type of model (Model 1) considers the FVs only, whereas the second type of model (Model 2) considers NFVs and MEV. The third type of model (Model 3) considers not only FVs, but also NFVs and MEV. The study tested the three hypotheses mentioned previously. 


\subsection{Logistic Regression Analysis}

The selected financial, non-financial and macroeconomic variables detailed above were used as independent variables for logistic regression analyses. The present study then used logistic regression analysis to establish three types of financial distress prediction models and to test related hypotheses.

According to Pallant [41], there are three assumptions underpinning the use of logistic regression. The first assumption refers to the number of cases in the sample and the number of independent variables included in the logistic regression model. Pallant [41] states that if the sample is small and has a large number of independent variables, the research might have problems with data analysis. As this was not the case, in our study, this assumption was met. The second assumption lies in checking for intercorrelations or multicollinearity among independent variables. The values of Pearson correlation reveal that the values of $r$ were all less than 0.9 (see Table 2). Consequently, multicollinearity did not appear to be an issue, and all of these factors were retained in the model. Third, as logistic regression is sensitive to outlying cases or outliers, such cases were identified and dealt with as per the procedure suggested by Tabachnick and Fidell [42].

Table 2. Pearson correlation of all variables.

\begin{tabular}{|c|c|c|c|c|c|c|}
\hline & $\begin{array}{c}\text { Gross } \\
\text { profit rate }\end{array}$ & $\begin{array}{c}\text { Debit } \\
\text { to total } \\
\text { assets }\end{array}$ & $\begin{array}{l}\text { Current } \\
\text { ratio }\end{array}$ & $\begin{array}{l}\text { The } \\
\text { Business } \\
\text { Climate } \\
\text { Index }\end{array}$ & $\begin{array}{l}\text { The frequency } \\
\text { of the firm } \\
\text { changing } \\
\text { auditor(s) }\end{array}$ & $\begin{array}{c}\text { The frequency of } \\
\text { auditors' report } \\
\text { with qualified } \\
\text { opinion/explanatory } \\
\text { paragraph }\end{array}$ \\
\hline Gross profit rate & 1.000 & & & & & \\
\hline Debit to total assets & -0.285 & 1.000 & & & & \\
\hline Current ratio & 0.229 & -0.845 & 1.000 & & & \\
\hline The Business Climate Index & 0.009 & 0.031 & -0.002 & 1.000 & & \\
\hline $\begin{array}{l}\text { The frequency of the firm } \\
\text { changing auditor(s) }\end{array}$ & -0.023 & 0.099 & -0.173 & -0.061 & 1.000 & \\
\hline $\begin{array}{l}\text { The frequency of auditors' } \\
\text { report with qualified } \\
\text { opinion/explanatory } \\
\text { paragraph }\end{array}$ & -0.378 & 0.434 & -0.346 & -0.128 & 0.253 & 1.000 \\
\hline
\end{tabular}

As stated earlier, we used 150 growth enterprises listed on the Hong Kong GEM during the period from 2000-2010 to build these three types of logistic regression models. Table 3 shows the logistic regression results for all of the models used in this study.

As discussed previously, for Model 1, the dependent variable (whether the growth enterprise experienced distress or not) was regressed on the three financial variables. For this model, consistent with prior expectations, the debt to total assets is positively associated with the probability of financial distress, whereas the gross profit rate and current ratio are negatively related to the probability of financial distress. For Model 2, the frequency of a firm changing its auditor(s) and the frequency of the firm's auditors' report with a qualified opinion/explanatory paragraph is positive and significant. Similarly, the Business Climate Index is positive and significant, which is also consistent with our expectations. Including FVs, NFVs and MEV, Model 3 has a greater pseudo $r$ squared than that of 
Models 1 and 2, which indicates better model fits in the logistic model. In this case, compared to the null model (the intercept-only model), Models 1-3 fit significantly better (in Model 1, chi-squared $=17.75$ on three degrees of freedom, probability $=0.0005$; in Model 2 , chi-squared $=67.21$ on three degrees of freedom, probability $=0.0000$; in Model 3, chi-squared $=73.65$ on six degrees of freedom, probability $=0.0000$ ). Additionally, according to Morris [43], in order to check how robust a model's predictive ability is, the model could be tested by using the validation tests, which includes the jackknife method.

Table 3. The results of logistic regression analysis.

\begin{tabular}{|c|c|c|c|}
\hline & Model 1 & Model 2 & Model 3 \\
\hline Intercept & $\begin{array}{l}-0.020 \\
(0.994) \\
\end{array}$ & $\begin{array}{c}31.45 \\
(0.062) *\end{array}$ & $\begin{array}{c}33.83 \\
(0.058) * \\
\end{array}$ \\
\hline Gross profit rate & $\begin{array}{c}-2.586 \\
(0.003) * * *\end{array}$ & & $\begin{array}{c}-2.713 \\
(0.028) * *\end{array}$ \\
\hline Current ratio & $\begin{array}{c}-0.246 \\
(0.795)\end{array}$ & & $\begin{array}{c}0.866 \\
(0.457)\end{array}$ \\
\hline Debt to total assets & $\begin{array}{l}1.418 \\
(0.468)\end{array}$ & & $\begin{array}{c}0.711 \\
(0.778)\end{array}$ \\
\hline The frequency of the firm changing its auditor(s) & & $\begin{array}{c}2.441 \\
(0.000) * * *\end{array}$ & $\begin{array}{c}2.549 \\
(0.000) * * *\end{array}$ \\
\hline $\begin{array}{l}\text { The frequency of auditors' report with qualified } \\
\text { opinion/explanatory paragraph }\end{array}$ & & $\begin{array}{c}3.711 \\
(0.001) * * * \\
\end{array}$ & $\begin{array}{c}3.226 \\
(0.009) * * * \\
\end{array}$ \\
\hline The Business Climate Index & & $\begin{array}{c}-6.502 \\
(0.049) * *\end{array}$ & $\begin{array}{c}-6.956 \\
(0.046) * * \\
\end{array}$ \\
\hline Pseudo r square & 0.096 & 0.366 & 0.401 \\
\hline Likelihood ratio chi square & 17.75 & 67.21 & 73.65 \\
\hline Probability $>$ chi square & 0.0005 & 0.0000 & 0.0000 \\
\hline
\end{tabular}

$*, * *, * * *$ indicates the $10 \%, 5 \%$ and $1 \%$ level of significance, respectively.

\subsection{Jackknife Method and the Validation of Logistic Models}

Validation tests examine the ability of the classification models to predict financial distress among a set of companies. Prior studies used various validation methods, including forecast validation test and the jackknife method. The present study used the jackknife method for validation, because it was widely applied in the literature for the validation of bankruptcy prediction models. This test is considered particularly useful to research studies that deal with relatively small sample sizes, since the entire sample can be used to derive the parameters. The test provides an almost unbiased estimate of the misclassification rate, and the statistical overfitting problem can be properly addressed [44].

Table 4 presents the validation results of the logistic model at different cut-off levels, including type I error (misclassification of a distressed firm as non-distressed), type II error (misclassification of a non-distressed firm as distressed), sensitivity (percentage of distressed firms correctly identified), specificity (percentage of non-distressed enterprises correctly identified), classification accuracy (percentage of enterprises correctly identified). The cut-offs from 0.05 to 0.40 are used based on the receiver operating characteristic curves, because during this interval, either the type I error or the type II 
error is relatively small. If the cut-offs fall outside this interval, either the type I error or the type II error increases rapidly.

Table 4. Jackknife method's validation results using different models.

\begin{tabular}{|c|c|c|c|c|c|}
\hline Cut-off & Type I Error & Sensitivity & Type II Error & Specificity & $\begin{array}{c}\text { Classification } \\
\text { Accuracy } \\
\end{array}$ \\
\hline \multicolumn{6}{|c|}{ Panel A: Classification accuracy for Model 1 at different cut-off points } \\
\hline 0.05 & $0.00 \%$ & $100.00 \%$ & $100.00 \%$ & $0.00 \%$ & $30.00 \%$ \\
\hline 0.10 & $4.44 \%$ & $95.56 \%$ & $98.10 \%$ & $1.90 \%$ & $30.00 \%$ \\
\hline 0.15 & $13.33 \%$ & $86.67 \%$ & $81.90 \%$ & $18.10 \%$ & $38.67 \%$ \\
\hline 0.20 & $22.22 \%$ & $77.78 \%$ & $32.38 \%$ & $67.62 \%$ & $46.00 \%$ \\
\hline 0.25 & $28.89 \%$ & $71.11 \%$ & $47.62 \%$ & $52.38 \%$ & $58.00 \%$ \\
\hline 0.30 & $35.56 \%$ & $64.44 \%$ & $32.38 \%$ & $67.62 \%$ & $66.67 \%$ \\
\hline 0.35 & $42.22 \%$ & $57.78 \%$ & $23.81 \%$ & $76.19 \%$ & $70.67 \%$ \\
\hline 0.40 & $46.67 \%$ & $53.33 \%$ & $14.29 \%$ & $85.71 \%$ & $76.00 \%$ \\
\hline \multicolumn{6}{|c|}{ Panel B: Classification accuracy for Model 2 at different cut-off points } \\
\hline 0.05 & $0.00 \%$ & $100.00 \%$ & $100.00 \%$ & $0.00 \%$ & $30.00 \%$ \\
\hline 0.10 & $2.22 \%$ & $97.78 \%$ & $69.52 \%$ & $30.48 \%$ & $50.67 \%$ \\
\hline 0.15 & $11.11 \%$ & $88.89 \%$ & $32.38 \%$ & $67.62 \%$ & $74.00 \%$ \\
\hline 0.20 & $24.44 \%$ & $75.56 \%$ & $20.95 \%$ & $79.05 \%$ & $78.00 \%$ \\
\hline 0.25 & $31.11 \%$ & $68.89 \%$ & $8.57 \%$ & $91.43 \%$ & $84.67 \%$ \\
\hline 0.30 & $31.11 \%$ & $68.89 \%$ & $8.57 \%$ & $91.43 \%$ & $84.67 \%$ \\
\hline 0.35 & $31.11 \%$ & $68.89 \%$ & $7.62 \%$ & $92.38 \%$ & $85.33 \%$ \\
\hline 0.40 & $31.11 \%$ & $68.89 \%$ & $7.62 \%$ & $92.38 \%$ & $85.33 \%$ \\
\hline \multicolumn{6}{|c|}{ Panel C: Classification accuracy for Model 3 at different cut-off points } \\
\hline 0.05 & $0.00 \%$ & $100.00 \%$ & $91.43 \%$ & $8.57 \%$ & $36.00 \%$ \\
\hline 0.10 & $2.22 \%$ & $97.78 \%$ & $55.24 \%$ & $44.76 \%$ & $60.67 \%$ \\
\hline 0.15 & $11.11 \%$ & $88.89 \%$ & $25.71 \%$ & $74.29 \%$ & $78.67 \%$ \\
\hline 0.20 & $22.22 \%$ & $77.78 \%$ & $19.05 \%$ & $80.95 \%$ & $80.00 \%$ \\
\hline 0.25 & $22.22 \%$ & $77.78 \%$ & $14.29 \%$ & $85.71 \%$ & $83.33 \%$ \\
\hline 0.2983 & $24.44 \%$ & $75.56 \%$ & $9.52 \%$ & $90.48 \%$ & $86.00 \%$ \\
\hline 0.30 & $26.67 \%$ & $73.33 \%$ & $9.52 \%$ & $90.48 \%$ & $85.33 \%$ \\
\hline 0.35 & $28.89 \%$ & $71.11 \%$ & $9.52 \%$ & $90.48 \%$ & $84.67 \%$ \\
\hline 0.40 & $31.11 \%$ & $68.89 \%$ & $7.62 \%$ & $92.38 \%$ & $85.33 \%$ \\
\hline
\end{tabular}

Panel A of Table 4 shows the overall percentage of correctly classified cases when the model included the three financial independent variables. The model with these independent variables correctly classified $30 \%$ of cases at the cut-off of 0.05 and $76 \%$ of cases at the cut-off of 0.40 . We also found that the values of sensitivity and specificity are $100 \%$ and $0 \%$, respectively, at the cut-off of 0.05 ; the values of sensitivity and specificity are $53.33 \%$ and $85.71 \%$, respectively, at the cut-off of 0.40 . In other words, at the cut-off of $0.4,24$ firms are correctly classified out of 45 distressed firms, and 90 firms are correctly identified out of 105 non-distressed firms.

Next, we checked whether the model's predictive ability increased after the inclusion of non-financial and macroeconomic variables. The jackknife method provided an overall prediction of how well the model with three non-financial and macroeconomic independent variables would perform compared 
with the model that considers three financial independent variables. For Model 2, the model with these independent variables correctly classified $30 \%$ of cases at a cut-off of 0.05 and $85.33 \%$ of cases at the cut-off of 0.40 . We also found the values of sensitivity and specificity are $100 \%$ and $0 \%$, respectively, at the cut-off of 0.05 ; the values of sensitivity and specificity are $68.89 \%$ and $92.38 \%$, respectively, at the cut-off of 0.40 . It was therefore an improvement over the classification accuracy of Model 1 at the cut-offs from 0.05 to 0.40 . Thus, the model that included non-financial and macroeconomic independent variables performed better than did Model 1 .

We then employed all of the variables - financial, non-financial and macroeconomic variables - to check whether there was further improvement in the predictive ability of the model. As mentioned previously, the jackknife method provided an overall prediction of how well the model with six financial, non-financial and macroeconomic independent variables would perform compared with Model 1 and Model 2. For Model 3, the model with these independent variables correctly classified $36 \%$ of cases at a cut-off of 0.05 and $85.33 \%$ of cases at a cut-off of 0.40 . We also found the sensitivity of $100 \%$ and specificity of $8.57 \%$ at the cut-off of 0.05 ; as well as the sensitivity of $68.89 \%$ and specificity of $92.38 \%$ at the cut-off of 0.40 . It was therefore an improvement over the classification accuracy of Model 1 at the cut-offs from 0.05 to 0.40 . Thus, the model that included non-financial and macroeconomic independent variables performed better than did Model 1. Model 3 performed better than did Model 2 at cut-offs from 0.05 to 0.30 , but the trend was not obvious at cut-offs from 0.30 to 0.40 . Nonetheless, Model 3's classification accuracy reaches a larger peak value of $86.00 \%$ at the cut-off of 0.2983 as compared to that of Model 2, which reaches a peak value of $85.33 \%$ at the cut-off of 0.35 . Hence, the model that included financial, non-financial and macroeconomic independent variables performed slightly better than did Model 2.

\subsection{Testing Hypotheses}

From the above, we conclude our findings with respect to the three hypotheses. We reject H1, as the classification accuracy of Model 2 is obviously higher than that of Model 1. H2 is also rejected, as Model 3 has larger classification accuracy vis-à-vis Model 1. Finally, we reject the third hypothesis, as Model 3's classification accuracy reaches a larger peak value of $86.00 \%$ at the cut-off of 0.2983 as compared to that of Model 2, which reaches a peak value of $85.33 \%$ at the cut-off of 0.35 .

\section{Results and Discussions}

A possible reason for the better predictive power of the above two models than the model that only considers FVs could be that growth enterprises may be prone to financial information, which may involve window-dressing. The need for such window-dressing is felt as these enterprises have to raise capital in the market. Bildersee and Kahn [45] suggested that enterprises that window-dress their financial data can be motivated by the desire of management to present a positive image. A case study of Wah Sang Gas (a growth enterprise) by He and Liu [46] reports that in 2004, it was suspended from trading on the GEM, and a huge administrative penalty was imposed, as the company had falsified its financial statements, which even included fake profit figures. There is no doubt that window-dressed financial data with fake information cannot reflect the real performance of growth enterprises [46,47]. 
Even more importantly, some institutional factors also affect auditors' judgment on growth enterprises' financial information. For instance, Hong Kong has been described as one of the least litigious regions in the world [48]. The lack of litigiousness severely restricts the ability of investors to bring lawsuits against auditors for alleged "audit failures" [49]. Apart from the legal barriers, the prevalence of Confucianism in Hong Kong has led to a culture of settling differences using negotiation instead of the formal legal system [50]. In summary, auditors are expected to perceive very limited litigation risk in Hong Kong. Hence, litigation risk would not be an important consideration in the decisions made by auditors when they exercise their judgments in issuing disclaimers as opposed to other alternatives in conditions characterized as distressed [51].

Another reason could be that some NFVs and MEVs are more relevant to financial distress prediction than are FVs for growth enterprises on the Hong Kong GEM. Kuo et al. [18] used NFVs along with FVs (but not MEVs) to overcome the unreliability or unavailability of SMEs' financial information. Furthermore, MEVs and some NFVs contain incremental information beyond FVs in predicting financial distress in some developing countries [52]. For instance, according to the published information revealed by the Hong Kong GEM, 13 distressed growth enterprises delayed releasing their financial statements before they experienced financial distress [46].

Our results are important, since the Hong Kong GEM is a unique market, for the reasons already explained earlier. Chan et al. [5] stated that at least 70\% of initial public offering stocks listed on the GEM are high-tech industries. It is needless to add that assessing the performance of these stocks based on only financial data could provide a lopsided picture of these enterprises, which constitute the majority of the growth enterprises. Consequently, the comprehensive models developed by us suggest the way forward and thereby contribute to advancement of the extant theory of distress prediction.

\section{Conclusions}

The present study constructs financial distress prediction models for growth enterprises on the Hong Kong GEM. One proposed financial distress prediction model takes not only financial variables into account, but also non-financial variables and macroeconomic variables. We advance the theory of financial distress prediction and propose a comprehensive financial distress prediction model, which is important for maintaining financial sustainability in the GEM.

We find that a logistic model that uses financial, non-financial and macroeconomic variables has a slightly higher predictive accuracy of financial distress than does the model that contains non-financial and macroeconomic variables only. We also find that the logistic model including only non-financial and macroeconomic variables has better predictive power compared to the model that only considers financial variables.

It is possible that growth enterprises on the GEM, which could potentially experience financial distress in the near future, may window-dress their financial statements. Our study suggests that regulators and policymakers of Hong Kong GEM need to pay more attention to growth enterprises that present financial data that apparently does not reveal any problem, but shows non-financial indicators that are adverse and face distressed macroeconomic conditions. Similarly, investors and stock analysts can benefit from the findings of the present study, because the findings would enable them to better assess the probability of the growth enterprises' financial distress. The investors or stock analysts who 
can obtain sufficient and reliable information of firm-specific non-financial and macroeconomic conditions should be able to forecast the financial distress of growth enterprises with higher accuracy and make better investment decisions.

External auditors may also have a role to play here. External auditors are often required to comment on the "going-concern" aspect of the audited firm. In arriving at their judgment, external auditors may wish to consider non-financial information and macroeconomic conditions, rather than just confining their attention to financial data. Such a business-risk approach to auditing is prevalent in developed economies. The findings of this study would also help investors to correctly assess the firm's financial risk and go beyond the financial data for distress prediction.

\section{Acknowledgments}

The authors are grateful to the anonymous reviewers for their insightful comments on this article. This work was financially supported by the Fundamental Research Funds for the Central Universities in China (No. 105274054), the Special Grant from the China Postdoctoral Science Foundation (No. 2014T70703) and the Social Science Research Fund (No. 14YJCZH055) from the Chinese Ministry of Education.

\section{Author Contributions}

Hui $\mathrm{Hu}$ collected the data and wrote the manuscript. Milind Sathye reviewed related studies and contributed to the manuscript draft and its revisions.

\section{Conflicts of Interest}

The authors declare no conflict of interest.

\section{References}

1. Vong, P.I.; Zhao, N. An examination of IPO underpricing in the growth enterprise market of Hong Kong. Appl. Financ. Econ. 2008, 18, 1539-1547.

2. The Stock Exchange of Hong Kong Ltd. (TSEHKL) About Growth Enterprise Market. Available online: http://www.hkgem.com/aboutgem/e_default.htm (accessed on 9 September 2014).

3. China Securities Regulatory Commission (CSRC). China Capital Markets Development Report; Financial Publishing House: Beijing, China, 2008.

4. Iezza, P. Financial Sustainability of Microfinance Institutions (MFIs): An Empirical Analysis. Master's Thesis, Copenhagen Business School, Copenhagen, Denmark, 2010.

5. Chan, P.T.; Moshirian, F.; Ng, D.; Wu, E. The underperformance of the growth enterprise market in Hong Kong. Res. Int. Bus. Financ. 2007, 21, 428-446.

6. Chen, L.; Sun, J.; Zhang, H. Performance change and its influence factors in initial public offerings: An empirical study on Hong Kong Growth Enterprise Market. Audit. Econ. Res. 2005, 20, 84-88.

7. Tuckman, H.P.; Chang, C.F. A methodology for measuring the financial vulnerability of charitable nonprofit organizations. Nonprofit Volunt. Sect. Q. 1991, 20, 445-460. 
8. Walker, R.; Jones, S. An alternative approach to identifying councils "at risk". Econ. Pap. 2006, 25, 347-357.

9. Dollery, B.E. Financial Sustainability in Australian Local Government: Problems and Solutions. Working Paper, University of New England, Armidale, 2009. Available online: https://www.une.edu.au/ _data/assets/pdf_file/0006/16791/03-2009.pdf (accessed on 8 December 2014).

10. The Stock Exchange of Hong Kong Ltd. (TSEHKL) GEM Listing Rules. Available online: http://www.hkgem.com/listingrules/e_default.htm (accessed on 9 September 2014).

11. Lu, Y.C.; Chang, S.L. Corporate governance and quality of financial information on the prediction power of financial distress of listed companies in Taiwan. Int. Res. J. Financ. Econ. 2009, 32, 114-138.

12. Pranowo, K.; Achsani, N.A.; Manurung, A.H.; Nuryartono, N. Determinant of corporate financial distress in an emerging market economy: Empirical evidence from the Indonesian stock exchange 2004-2008. Int. Res. J. Financ. Econ. 2010, 52, 80-88.

13. Beaver, W. Financial ratios as predictors of bankruptcy. J. Account. Res. 1966, 4, 71-102.

14. Beaver, W. Market prices, financial ratios, and the prediction of failure. J. Account. Res. 1968, 8, 179-192.

15. Altman, E.I. Financial ratio discriminant analysis and the prediction of corporate bankruptcy. J. Financ. 1968, 23, 589-609.

16. Altman, E.I.; Haldeman, R.G.; Narayanan, P. Zeta analysis: A new model to identify bankruptcy risk of corporations. J. Bank. Financ. 1977, 1, 29-54.

17. Ohlson, J. Financial ratios and the probabilistic prediction of bankruptcy. J. Account. Res. 1980, 18, 109-131.

18. Kuo, H.C.; Wang, L.H.; Sheu, H.J.; Li, F.K. Credit evaluation for small and medium-sized enterprises by the examination of firm-specific financial ratios and non-financial variables: Evidence from Taiwan. Rev. Pac. Basin Financ. Mark. Policies 2003, 6, 5-20.

19. Wu, C.Y. Using non-financial information to predict bankruptcy: A study of public companies in Taiwan. Int. J. Manag. 2004, 21, 194-201.

20. Steyn-Bruwer, B.W.; Hamman, W.D. Company failure in South Africa: Classification and prediction by means of recursive partitioning. S. Afr. J. Bus. Manag. 2006, 37, 7-18.

21. Cheng, J.H.; Yeh, C.H.; Chiu, Y.W. Improving Business Failure Predication Using Rough Sets with Non-financial Variables. In Proceedings of the International Conference on Adaptive and Natural Computing Algorithms, Warsaw, Poland, 11-14 April 2007.

22. Mensah, Y.M. An examination of the stationary multivariate bankruptcy prediction models: A methodological study. J. Account. Res. 1984, 22, 380-395.

23. Dionne, G.; Laajimi, S.; Mejri, S.; Petrescu, M. Estimation of the default risk of publicly traded companies: Evidence from Canadian data. Can. J. Adm. Sci. 2008, 25, 134-152.

24. Slowinski, R.; Zopounidis, C. Application of the rough set approach to evaluation of bankruptcy risk. Intell. Syst. Account. Financ. Manag. 1995, 4, 27-41.

25. Dimitras, A.I.; Slowinski, R.; Susmaga, R.; Zopounidis, C. Business failure prediction using rough sets. Eur. J. Oper. Res. 1999, 114, 263-280.

26. Wilkins, M.S. Technical default, auditors' decisions and future financial distress. Account. Horiz. 1997, 11, 40-48. 
27. Chen, H.H. The timescale effects of corporate governance measure on predicting financial distress. Rev. Pac. Basin Financ. Mark. Policies 2008, 11, 35-46.

28. Ooghe, H.; Balcaen, S. Are failure prediction models widely usable? An empirical study using a Belgian dataset. Multinatl. Financ. J. 2007, 11, 33-76.

29. Aziz, A.M.; Humayon, A.D. Predicting corporate bankruptcy: Where we stand? J. Corp. Gov. 2006, $6,18-33$.

30. Balcaen, S.; Ooghe, H. Thirty-five years of studies on business failure: An overview of the classic statistical methodologies and their related problems. Br. Account. Rev. 2006, 38, 63-93.

31. Barnes, P. The analysis and use of financial ratios: A review article. J. Bus. Financ. Account. 1987, 14, 449-461.

32. Jones, S.; Hensher, D.A. Predicting firm financial distress: A mixed logistic model. Account. Rev. 2004, 79, 1011-1038.

33. Smith, M. Performance Measurement and Management: A Strategic Approach to Management Accounting; Sage: London, UK, 2005.

34. Back, P. Explaining financial difficulties based on previous payment behavior, management background variables and financial ratios. Eur. Account. Rev. 2005, 14, 839-868.

35. Foster, G. Financial Statement Analysis; Prentice-Hall International Editions: Englewood Cliffs, NJ, USA, 1986.

36. Lennox, C. Identifying failing companies: A re-evaluation of the logistic, probit and MDA approaches. J. Econ. Bus. 1999, 51, 347-364.

37. Kimmel, P.D.; Carlon, S.; Loftus, J.; Mltrione, L.; Kieso, D.; Weygandt, J.J. Accounting: Building Business Skills; John Wiley and Sons: Milton, Australia, 2006.

38. Weygandt, J.J.; Chalmers, K.; Mltrione, L.; Fyfe, M.; Kieso, D.; Kimmel, P.D. Principles of Financial Accounting; John Wiley and Sons: Milton, Australia, 2007.

39. Keasey, K.; Watson, R. Non-financial symptoms and the prediction of small business failure: A test of Argenti's hypothesis. J. Bus. Financ. Account. 1987, 14, 535-553.

40. Whitaker, R.B. The early signs of financial distress. J. Econ. Financ. 1999, 23, 123-132.

41. Pallant, J. SPSS Survival Manual: A Step-by-Step Guide to Data Analysis Using SPSSfor Windows; Open University Press: Maidenhead, UK, 2007.

42. Tabachnick, B.G.; Fidell, L.S. Using Multivariate Statistics; Pearson Education: Boston, MA, USA, 2007.

43. Morris, R. Early Warning Indicators of Corporate Failure; Ashgate: Aldershot, UK, 1997.

44. Lachenbruch, P. Discriminant Analysis; Hafner Press: New York, NY, USA, 1975.

45. Bildersee, J.; Kahn, N. A preliminary test of the presence of window dressing: Evidence from institutional stock trading. J. Account. Audit. Financ. 1987, 2, 239-256.

46. He, J.; Liu, Z. The illegal behaviours of Hong Kong GEM firms: Features and regulations. Secur. Mark. Herald 2008, 7, 17-25.

47. Xin, S. Hong Kong Growth Enterprise Market developing in a tight corner. Shenzhen Stock Exch. Mon. 2008, 1, 62-65.

48. International Federation of Accountants (IFA). Auditors' Legal Liability in the Global Marketplace: A Case for Limitation; IFA: New York, NY, USA, 1995. 
49. Ho, B.M. Rethinking the system of sanctions in the corporate and securities law of Hong Kong. McGill Law J. 1997, 42, 603-648.

50. Peng, S.Y. The WTO legalistic approach and East Asia: From the legal culture perspective. Asian-Pac. Law Policies J. 2000, 1, 78-118.

51. Lam, K.C.K.; Mensah, Y.M. Auditors' decision-making under going-concern uncertainties in low litigation-risk environments: Evidence from Hong Kong. J. Account. Public Policy 2006, 25, 706-739.

52. Tsai, B.H.; Lee, C.F.; Sun, L. The impact of auditors' opinions, macroeconomic and industry factors on financial distress prediction: An empirical investigation. Rev. Pac. Basin Financ. Mark. Policies 2009, 12, 417-454.

(C) 2015 by the authors; licensee MDPI, Basel, Switzerland. This article is an open access article distributed under the terms and conditions of the Creative Commons Attribution license (http://creativecommons.org/licenses/by/4.0/). 